\title{
Research on the Influence of the University City Town Construction in Huaxi Guizhou on the Regional Sustainable Development
}

\author{
Miao Yinjia, He Jin, Wang Zhenhui, Liuning, Niu Xinyuan, Du Xi, Xu wei \\ Guizhou University, Guiyang, Guizhou, China \\ Yinjia9@163.com
}

Keywords: the University City Town, region, sustainable development, influence.

\begin{abstract}
By field survey, literature research and other methods, the research group takes the University City Town of Huaxi as an example to explore the relationship between the University City Town construction and regional development. The research group has studied and found that with a collection of urban modern origin and the development of higher education idea the University City Town of Huaxi Guiyang has its unique advantages in the regional development. It will have far-reaching influence on the development of the regional politics, economics, cultures and ecology.
\end{abstract}

\section{Introduction}

The University City Town of Huaxi Guiyang is located in the scope of Guizhou Gui'an colleges and universities gathered area. The Southern District of colleges and universities gathered area is composed of Guizhou University and Guizhou Minzu University. And the Southern District is located in the scope of Dangwu Town in Gui'an New District, and it is composed of nine colleges and universities, such as Guizhou Normal University, Guizhou University of Finance and Economics, Guiyang Medical College, Guiyang College of Traditional Chinese Medicine, Guizhou Institute of Light Industry, Guizhou Minzu University, Guizhou City Vocational College, Institute of Humanities Science and Technology of Guizhou Minzu University, Guizhou Institute of Technology and so on. The Southern District is commonly known as " the University City Town of Huaxi”. By the field survey, literature research and other methods, we take the University City Town of Huaxi as the example to explore the relationship between the University City Town construction and regional development, so we will make a summary of the influence of the University City Town Construction in Huaxi Guizhou on the regional development.

\section{The Influence of the University City Town Construction in Huaxi Guizhou on the Regional Economic Development}

By "Talent Highland" construction we integrate Guizhou education resources to provide intelligence and talent support for Gui'an New District construction and Huaxi District economic development. The University City Town has effectively integrated the quality resources of higher education in Guizhou and has expanded the scale of higher education. After the completion of the University City Town, it will contribute nearly 4\% to increase the gross enrollment rate of higher education in Guizhou. Currently 5 colleges and universities settled down in the University City Town have initially realized intensive school-running mode of sharing with the resources of books, electronic networks, laboratories, public teaching, mutual teachers and others. With the establishment of scientific research cooperation, mutual recognition of credits and other mechanisms among colleges and universities, Guizhou higher education resources with good quality will be further effectively integrated to make it be a gathering area for Guizhou high level talents and a new platform of high-tech research and development. Thus it becomes a bright window to display education, culture, science and technology development in Guizhou. And it will provide strong and powerful intelligence and talent support for construction and development of Gui'an New District. Construction of Huaxi University City Town makes the rapid growth of population number so as to make the consumer market of Huaxi District be expanded. And it makes 
the original economy scale can't meet the students' consumption. So there will be some new places which are suitable for the students' consumption near University City Town.

According to the field survey, these places of consumption are mainly banks, restaurants, grocery stores and so on. Because Huaxi University City Town has been built in a shot time, some industries still do not appear. However, with the guidance of these demands, these industries have gradually developed. The research group has done some statistics on the average consumption of the college students in Huaxi University City Town. According to the statistics, we find that the average consumption of each college student in University City Town is perhaps 1000 Yuan per month. We can roughly figure out that the average consumption of each student is 10000 Yuan or so per year. Then the total annual consumption is up to 2 billion yuan. If we add the consumption of teachers, teaching staff and so on, a huge market with consumption which is more than 2 billion yuan will eventually form. And new students with the number of 0.2 million will vigorously promote and stimulate the economic development of Huaxi District.

We promote the innovation by "Kechuang base"construction in Huaxi University City Town to promote the development of big data era in Guizhou and build a "new normality of economic development in Guizhou. 11 colleges and universities settled down in the University City Town cover science, engineering, agriculture, medicine, literature, economics, management, law, education, history the nine categories of subjects. They have a doctoral degree point of six disciplines, 2 academician workstations, a national experimental teaching demonstration center with the type of economic management, 1 national innovation experimental area of talented person with training mode, 1 innovation team for " Ministry of Education Yangtze River Scholars and Innovation Team Development Plan”, 1 national engineering technology research center, 1 laboratory for the common building of state and local, China Guizhou Information Park with Telecom Cloud Computing, Foxconn (Guizhou) Green Industrial Park with the Fourth Generation and so on. All the things mentioned above will provide a powerful intellectual support for pulling sustainable development of local economy. The innovative entrepreneurial project of college students bulit cooperatively by the Guizhou University of Finance and Economics in the University City Town and Guiyang Infobird Cloud Computing Technology co., LTD, namely "the world tree" cloud call center, has started and operated on May 25, 2014. And "the world tree" cloud call center is a beginning of the cooperation between Guizhou University of Finance and Economics in the University City Town and Guiyang Infobird Cloud Computing Technology co., LTD. The both parties will carry on further cooperation in a wider field to provide talent guarantee for the arrival of the era of big data in Guizhou. With the continuous improvement of the high altitude of the highlands with scientific and technological innovation in Huaxi University City Town, its "new engine", "engine” influence on economic and social development of Gui'an New District will be further apparent. It will further promote the adjustment of industrial structure in Guizhou and the development of the era of big data, and create "new normality" of economic development in Guizhou so as to promote Guizhou economy to go into the development upgrade.

The construction and development of the Huaxi University City Town will increase the intensity and depth of Guizhou's opening to the outside world. In 2014 Gui'an New District, provincial education department, the China-ASEAN Center and Southeast Asia Minister of Education Organization (SEAMEO) jointly held the 7th China - ASEAN Education Exchange Week in the University City Town. Relying on China - ASEAN Education Exchange week, the Huaxi University City Town will further deepen the cooperation with all ASEAN countries about language teaching, student exchanges, science and technology innovation, skillful talents training and other aspects. And it will make the education as the link to further strengthen the cooperation with ASEAN countries in economy, trade, tourism, culture and other fields to improve the breadth and depth of cooperation with ASEAN countries in Guizhou.

According to the investigation of research group, the construction and development of the University City Town will promote the construction of Shanghai Pudong International Talent City Gui'an base which is jointly built by Gui'an New District and Shanghai Pudong New District. It will make use of the global network of Shanghai Talent City to promote talent flow and build 
international employment platform for the college graduates in the University City Town. And it will jointly build college Entrepreneurship Forum and college students entrepreneurship Park with Huarun group to promote the development of small and micro enterprises in Guizhou and stimulate the vitality of private economy in Guizhou. We should plan to build international famous university campus with three phases in the University City Town to introduce international famous universities to set up branch schools in Huaxi University City Town so as to improve the scientific research level of international education in Guizhou. Seen from this we can know that the construction and development of Huaxi University City Town has greatly improved the level of opening to the outside world about economics and society in Guizhou so that it has laid a solid foundation for achieving the goal of "the latter surpassing the former and getting synchronous well-off” about Guizhou development.

\section{The Relationship between the Construction of Huaxi University City Town and the Regional Culture}

Huaxi University City Town which has brought together more than 10 colleges and universities is not only the important camp of knowledge innovation and knowledge dissemination but also is the cradle of cultivating talents with innovative spirit. What's more, it is an important source of culture innovation. By multicultural inclusion, integration and other advantages, Huaxi University City Town inherits and discards the cultures from different regions and different ethnics. It gets rid of the stale and brings forth the fresh to further promote the prosperity and development of the regional culture.

Making use of the advantage of regional agglomeration, Huaxi University City Town promotes the promotion of cultural communication between colleges and universities to promote regional culture. After the University City Town is built, on the one hand, it stems from the advantages of "openness and sharing" so as to attract experts and scholars with different countries, different nationalities, different cultures, different regions, different religions, different academic views to gather here. On the other hand, due to the openness of the space it makes the campus culture form natural circulation between the regions and regional areas. In addition, after the completion of Huaxi University City Town it will make the penetration for regional material culture and spiritual culture by the education resources between schools, such as the sharing of library resources, the courseware resources and teacher resources so as to enhance the regional culture.

Using existing regional tourism culture resources to dig into its potential value so as to further promote the development of regional culture. Huaxi University City Town not only has long running-school histories and campus culture with sincere cultural heritages from colleges and universities but also has the tourism culture resources formed by Tianhe Lake, ten-mile River Benchland, cultural landscape. It has Buyi folk culture with a strong local flavor. It should make full use of university cluster advantages to make a new interptretation and extension of the existing regional culture. Thus, it can not only promote the development of the local culture of the region but also can promote the development of related cultural industries to further enhance the cultural taste of Huaxi District and Guizhou area.

\section{The construction of Huaxi University City Town will promote regional political democratization and the construction of the regional harmonious society.}

As a main body for social service condensed education, scientific research, cultural exchange, and other functions, the functional essence of Huaxi University City Town and the concept of scientific development, building a harmonious society, the "three represents" and our party's guiding ideology are the same on the main objectives and major tasks. The construction of the University City Town constantly plays its function to fulfill the party's ideological guidance route so as to comprehensively promote the construction of regional political civilization. 
As a communication center of ideas and the source of new ideas, a wealth of high-quality talented people have gathered in Huaxi University City Town. When they leave school, they are likely to become the leaders in various fields, various industries and various disciplines. By various forms of political participation and discussing politics, they influence government decision-making and administration so as to vigorously promote the decision-making and administration of the regional government scientifically, professionally and democratically. In this way it promotes the level of the decision-making and administration of the regional government to a great extent to promote regional political civilization.

The University City Town will create the education environment, humanistic environment and cultural environment of establishing socialist core value view, cultivating civilized moral vogue and creating a positive and healthy public opinion atmosphere to make it become the spirit ladle mixture to condense the will of the people and promote social harmony. Thus, it can promote the construction speed of regional harmonious society.

\section{The construction of Huaxi University City Town will increase employment opportunities and promote social employment.}

The construction of the University City Town will make the number of students increase. Thus, the consumer market of Huaxi District will expand. Thisis bound to promote the process of logistics socialization reform in colleges and universities and develop the social service system and Logistics support system (including the cafeteria, dormitory, communication and so on) of school surrounding areas so as to increase employment opportunities. The construction of Huaxi University City Town makes the scale of the economy near the university can not meet the consumption of college students. So there will be some new places which are suitable for the consumption of college students near the University City Town. According to our survey, it shows that these new consumption places are mainly banking services, catering, shopping and so on. Although some of industries haven't appear near the University City Town, according to the orientation of demand, these industries will develop slowly.

In our survey about "Which aspects about the functions do you think need us to urgently improve" it shows that main aspects which the University City Town urgently needs to improve are banking services, restaurants, entertainment, transportation, medical care, shopping and so on. The demands of these industries from the University City Town make industries and positions about employment for Huaxi District residents increase so as to increase employment opportunities for the Huaxi District residents.

\section{The construction of Huaxi University City Town will promote the construction and development of ecological civilization in Guiyang}

Hu Jintao, general secretary, has put forward in the Eighteenth People's Congress Report that we should vigorously promote the construction of ecological civilization. That is to say, he gives the direction for the scientific planning of University City Town. Along with the advancement of the whole ecological civilization construction of Chinese society, the planning and construction of ecological University City Town will also become the mainstream of the University City Town construction. But we should also see that using single planning to highlight the concept of ecological civilization construction is not enough. Only we guide it by education, publicity and practice to make ecological civilization be rooted in regional students, surrounding businesses and people we can truly promote the harmonious development of the region.

The construction idea and direction of Huaxi University City Town accord with the requirements of ecological civilization construction in China at present. The planning about the construction of Huaxi University City Town adheres to the overall planning idea, namely "green trees are around the greek and books Elegant overflows the campus". It makes full use of advanced planning concepts and architectural techniques to make the project construction combine with green mountains and rivers and national culture. Thus, it highlights mountains and water landscape and 
has outstanding style. In this way it not only respects the teaching requirements of teachers and students in colleges and universities but also tries to protect the ecological environment. It makes organic integration of the development of educational industry and urban construction, natural ecology and national culture. It is really "green mountains and rivers go around the town, and the sounds of reading books and laughters overflow the campus". The low carbon environmental protection in our country, water circulation, geothermal energy, the conversion of wind and light energy and other ecological environmental protection projects have started to construct. Jinniu Lake Tourism Park, Si Ya River Wetland Cultural Park, Yelang Valley Folk Ecological Park and Doufeng Hill Sports and Leisure Park are going to take great efforts to construct, so the University city Town will be built a "landscape place and rural city".

The construction of Huaxi University City Town pays great attention to carry forward and cultivate ecological culture, and construct the education system of ecological civilization. Ecological culture is the basis and soul of the construction of ecological civilization development. By voluntary tree planting activities about "the forest in colleges and universities" of million people, Huaxi University City Town has built the forest of national unity. It is beneficial to carry forward and cultivate ecological culture, guide the formation of value orientation about ecological civilization in the whole society and correct, healthy production, living and consumption behavior. Thus, the campus atmosphere about everyone concerned and all involved in the construction of ecological civilization will form. It has the vital significance for Guizhou province to build demonstration area of ecological civilization and go to the new era of ecological civilization.

We combine the construction of Huaxi University City Town and the construction of Gui'an New District to build "ecological corridor", and promote the ecological development of industries in Gui'an New District. Combined with the construction of Gui'an New District, about campus virescence planning Huaxi University City Town sets about from the four aspects of ecology, function, landscape and development to construct ecological saving green space with glorious, unified and colorful overall style. We use the rich and varied landscape rhythm to enhance the landscape effect of green corridor, and make the surrounding roads around the University City Town be constructed to be ecological road, landscape road, environmental protection road with the features of colorful ecological landscape. Each place is permeated with the concept of "integrating the beauty of the natural landscape, creating the road of ecological civilization, constructing green mountains and water town and landscape city". Broad city road, beautiful "green ecological corridor", poetic habitated "Switzerland of the east", all the things mentioned above make Industry bosses who invest in Gui' an New District have the feelings of astonishment and joy to make them decide to promote their own industry to realize ecological development in the new city of green ecological industrialization.

Huaxi University City Town strengthens the exchange and cooperation of ecological civilization to promote the construction of ecological civilization demonstration zone in Guizhou. December 13, 2013 Guizhou Province and Beijing University have signed the Cooperation Framework Agreement between Beijing University and Guizhou Provincial People's Government, namely Gui'an New District and Beijing University jointly construct Guizhou ecological civilization city in Huaxi University City Town to make it as demonstration centers in advance of the national ecological civilization about Guizhou construction. Relying on the project, the construction of Huaxi University City Town strengthen exchanges and cooperation in ecological civilization. It and Beijing University jointly construct Institute of International Studies about ecological civilization, and it combines with Stanford University in USA, University of London, Hebrew University of Jerusalem in Israel, and other 10 famous universities in the world establish the international alliance for a green university. It will provide decision- making references and talents supports for the construction and development of ecological civilization in Guizhou to promote research and education of the global ecological civilization.

Today's Guizhou Huaxi University City Town builds “the three big platforms” of talent exchange, scientific and technological innovation, education cooperation to accelerate the construction of science and technology innovation demonstration area and actively construct the 
open mode of economic development. And it marches forward with big strides to the goal of creating a "talents highland, science and technology innovation base, ecological area". Carrying the dream of "strong talents of Guizhou province", "catching up with others from backwardness" and "synchronous well-off”, a fully functional talent "heights" in Guizhou with beautiful environment is rising in "Pearl of the plateau", Gui'an New District. It will provide strong and powerful source of power for Guizhou Province to have further development and realize the backwardness to catch up with others. It will greatly promote Guizhou economic construction, political construction, cultural construction, social construction, the construction of ecological civilization and promote the development of Guizhou's economic and social "new normality”.

\section{References}

[1] Li Xiangzhu. The Influence of the University City Town Construction on the Regional Politics, Economics and Cultures [A]. Journal of shanxi agricultural university, 2012.

[2] Luo Kunjin. The Research on Sharing Model about Education Resource of University Campus [A]. Economic and Social Development, 2012.

[3] Peng Huifang, etc. The Theory and Practice Exploration of Course Resources Sharing in Guangzhou University Town [J]. Higher Education Formula, 2008.

[4] Written by Clark . Kerr, and translated by Chen Xue. The Use of Colleges [M]. Nanchang: Jiangxi Education Press, 1993.

[5] Li Tiefang. The Perspective on the Relationship between Higher Education and Culture [J]. University Education Science, 2003.

[6] Zhang Zhenzhu. The Construction of University City Town Makes the Higher Education and Regional Economic Win-win[J]. Journal of National Institute of Education Administration, 2003.

[7] Zheng Yajuan. The Countermeasure Research on Higher Education Park and Regional Economy Coordination Development [J]. Vocational and Technical Education, 2004.

[8] Gao Shan., Wang Jingmei. Rational Thinking for the Sustainable Development of the University City Town [J]. Education Development Research, 2007. 